\title{
Edukasi Stimulasi Perkembangan Melalui Pijat Bayi di Dusun Jati
}

\author{
Era Revika $^{1}$, Yuni Fitriana ${ }^{1}$ \\ ${ }^{1}$ Prodi DIII Kebidanan, Sekolah Tinggi Ilmu Kesehatan AKBIDYO, Yogyakarta, Indonesia \\ e-mail: 1revika13@gmail.com, ${ }^{1}$ yunifitriana2906@gmail.com
}

\begin{abstract}
ABSTRAK Sumber daya yang berkualitas menentukan kemajuan bangsa, salah satu upaya yang dilakukan adalah dengan memperhatikan stimulasi pertumbuhan dan perkembangan anak yang dimulai dari masa bayi, Perkembangan anak tersebut akan lebih optimal bila sejak bayi mendapatkan stimulasi karena hal ini dapat mempengaruhi terhadap kemampuan yang dimiliki seorang anak sesuai dengan usia nya. Pijat adalah cara melakukan stimulasi perkembangan pada bayi melalui tehnik sentuhan. Periode penting pada pertumbuhan dan perkembangan anak dapat menentukan kualitas generasi dimasa mendatang, Masa ini pertumbuhan dasar akan mempengaruhi dan menentukan pertumbuhan dan perkembangan selanjutnya. Agar anak dapat mencapai pertumbuhan yang optimal, maka diperlukan suatu bentuk perawatan yang lebih intensif diantaranya berupa sentuhan dan stimulasi yang terus-menerus. Salah satunya adalah dengan pemberian massage. Massage merupakan upaya pemenuhan kebutuhan anak baik secara fisik, kasih sayang serta stimulasi mental. Apabila terjadi kelainan pertumbuhan dan perkembangan secara dini maka penatalaksanaan akan lebih dini mudah dilakukan. Berdasarkan hal tersebut tersebut maka perlu adanya kegiatan pengabdian kepada masyarakat dengan tujuan memberikan edukasi tentang stimulasi perkembangan melalui pijat bayi pada ibu-ibu yang mempunyai bayi dan anak. Metode yang digunakan dalam kegiatan ini adalah dengan memberikan edukasi cara menstimulasi perkembangan bayi dengan pijat bayi terhadap ibu ibu khususnya yang mempunyai bayi maupun anak usia 1 tahun dengan demonstrasi, diskusi serta Tanya jawab tentang stimulasi perkembangan anak melalui pijat bayi. Para peserta sangat antusias pada saat pelaksanaan hal ini tampak peserta aktif pada saat diskusi, serta pada saat dilakukan demonstrasi para ibu-ibu memperhatikan lalu mengikuti gerakan pijat bayi secara langsung untuk dipraktekkan kepada bayinya. Para peserta menjadi lebih paham akan pentingnya stimulasi perkembangan pada bayi dan anak melalui pijat yang dilakukan oleh orangtua sendiri karna selain dapat membuat relaksasi juga akan membentuk bounding antara ibu dan bayi.
\end{abstract}

KATA KUNCI stimulasi; perkembangan; pijat bayi

ABSTRACT Quality human resources determine the future of the nation. Stimulation of growth and development of children from an early age (infancy) is one of the efforts to improve the quality of human resources. Stimulation in infancy can optimize child development because it helps adjust the child's ability and age. Massage is a stimulation of the baby's development through tactile techniques. An important period of children's growth and development can determine the quality of future generations. Basic growth will influence and determine future growth and development. Optimal growth requires more intensive care such as touch and continuous stimulation. One of them is massage. Massage is an effort to fulfill the stimulation needs of children both physically, 
affectionately, and mentally. Early detection of growth and development abnormalities facilitates the management of stimulation. Based on this, it is necessary to have community service activities aimed at educating developmental stimulation through baby massage. Implementation of education in this activity is carried out through demonstrations, discussions, and questions and answers about the stimulation of child development through baby massage. This activity involves (especially) mothers with 1-year-old babies. The participants were very enthusiastic to participate in this activity. It can be seen from their activeness in discussions and demonstrations. In the demonstration process, the mothers pay attention, follow, and practice baby massage directly to their babies. The participants finally understood the importance of massage stimulation in the development of infants and children.

KEYWORDS stimulation; development; baby massage

\section{Pendahuluan}

Berdasarkan Keputusan Menteri Kesehatan Nomor 28 tahun 2017 tentang Izin dan Penyelenggaraan Praktek Bidan menyebutkan bahwa bidan berwenang Pemantauan tumbuh kembang bayi, anak balita, dan anak prasekolah meliputi kegiatan penimbangan berat badan, pengukuran lingkar kepala, pengukuran tinggi badan, stimulasi deteksi dini, dan intervensi dini peyimpangan tumbuh kembang balita dengan menggunakan Kuesioner Pra Skrining Perkembangan (KPSP). Konseling dan penyuluhan meliputi pemberian komunikasi, informasi, edukasi (KIE) kepada ibu dan keluarga tentang perawatan bayi baru lahir, ASI eksklusif, tanda bahaya pada bayi baru lahir, pelayanan kesehatan, imunisasi, gizi seimbang, PHBS, dan tumbuh kembang. [2] salah satu upaya untuk menstimulasi perkembangan adalah dengan melakukan pijat atau massage. Tujuan dilakukan pijat bayi adalah untuk memaksimalkan pertumbuhan dan perkembangan bayi dengan memberikan stimulasi raba, gerak dan stimulasi lainnya hal ini dilakukan dalam suasana atau keadaan yang menyeangkandan nyaman [5]. Hal tersebut dapat disimpulkan bahwa kegiatan stimulasi melalui pijat bayi adalah suatu stimulasi yang membuat bayi nyaman serta apabila dilakukan sendiri oleh ibu dapat menimbulkan kedekatan antara bayi dan ibu bayi. Ikatan batin yang sehat sangat penting bagi anak terutama dalam usia 2 tahun pertama yang akan menentukan perkembangan kepribadian anak selanjutnya [1].

Pemantauan pertumbuhan, perkembangan dan gangguan tumbuh kembang anak dimaksudkan untuk meningkatkan kualitas tumbuh kembang anak usia dini dan kesiapan anak memasuki jenjang pendidikan formal [3] Perkembangan anak akan optimal bila sejak bayi mendapatkan perhatian dan stimulasi pertumbuhan dan perkembangan yang cukup. Bayi yang dapat rangsangan secara tepat dan berkesinambungan akan mempengaruhi perkembangan otaknya [4] . Pijat bayi merupakan terapi sentuh, jika dilakukan secara rutin akan membantu pertumbuhan emosi fisik dan emosi bayi disamping juga mempertahankan kesehatannya [6].dengan demikian banyak manfaat yang diperoleh dengan malakukan pijat pada bayi, hal ini perlu adanya edukasi sehingga orangtua lebih memahami manfaat yang dirasakan tentang pijat bayi.

Periode penting pada pertumbuhan dan perkembangan anak dapat menentukan kualitas generasi dimasa mendatang, Masa ini pertumbuhan dasar akan mempengaruhi dan menentukan pertumbuhan dan perkembangan selanjutnya. Agar anak dapat mencapai pertumbuhan yang optimal, maka diperlukan suatu 
bentuk perawatan yang lebih intensif diantaranya berupa sentuhan dan stimulasi yang terus-menerus. Salah satunya adalah dengan pemberian massage. Massage merupakan upaya pemenuhan kebutuhan anak baik secara fisik, kasih sayang serta stimulasi mental [1].

Tujuan dari pelaksanaan kegiatan ini adalah untuk memberikan edukasi pada orangtua khususnya yang memiliki bayi agar dapat mengoptimalkan cara stimulasi perkembangan anak melalui pijat bayi. Dusun jati khususnya RT.07 merupakan penduduk modern yang tinggal diperumahan, dengan latar belakang ibu muda yang bekerja diluar rumah, komunitas yang mana banyak terdapat balita yang mana anggapan bahwa pelaksanaan pijat bayi hanya dapat dilakukan oleh tukang pijat atau dukun, padahal pijat bayi dapat dilakukan orangtua agar lebih meningkatkan kedekatan antara bayi dan orangtua. Ibu muda ini menemui kendala karena sibuk bekerja dan tidak mengetahui cara memproduksi ASI lebih banyak karena bayinya sering rewel bahkan perkembangan bayinya cukup lambat dibandingkan bayi lainnya. Usia 4 bulan yang harusnya sudah bisa tengkurap namun bayinya baru miring-miring akibat sering digendong karena rewel ditinggal bekerja. Ikatan bayi dan ibu kurang tercipta karena bayi sering dipijat oleh orang lain, olehkarena itu perlunya memberikan edukasi stimulasi perkembangan bayi melalui pemijatan.

\section{Metode}

Metode yang digunakan dalam pelaksanaan pengabdian kepada masyarakat ini adalah:

a. Tahap persiapan

1) Penyusunan proposal

2) Pengajuan surat ijin pelaksanaan

3) Koordinasi dengan Ketua paguyuban Dusun

4) Menyusun materi

5) Final check persiapan pelaksanaan pengabdiaan

b. Tahap pelaksanaan

Metode yang digunakan dalam kegiatan ini berupa diskusi tentang pemahaman pijat bayi serta Demonstrasi cara menstimulasi perkembangan dengan melakukan pijat bayi. Media yang digunakan adalah phantom bayi dan oil dimana aman untuk bayi serta selimut bayi. Peserta pada kegiatan ini adalah ibu-ibu yang mempunyai bayi dan anak didusun Jati. Kegiatan ini dilaksanakan pada hari Sabtu, 16 Maret 2019 pukul 15.00 WIB di rumah warga Dusun Jati Kelurahan Wonokromo Kecamatan Pleret dengan jumlah sasaran peserta yaitu 27 orang ibu.

c. Tahap akhir

1) Evaluasi pelaksanaan kegiatan pengabdian

2) Rencana tindaklanjut kegiatan

3) Menyusun laporan pengabdian

\section{Hasil dan Pembahasan}

Kegiatan pengabdian kepada masyarakat sebagai salah satu upaya pemantauan pertumbuhan dan perkembangan melalui pijat atau massage disambut baik ibu-ibu dusun Jati, hal ini dapat terlihat dari jumlah kehadiran dari para peserta. Pelaksanaan diawali dengan mengisi daftar hadir kemudian di lanjutkan dengan brainstorming tentang pijat bayi, diskusi pelaksanaan pijat bayi, sebelum pemberian edukasi kegiatan dimulai dengan saling diskusi dan berbagi pengalaman tentang apa itu pijat bayi, dari diskusi ini tampak bahwa pijat bayi 
tidak asing lagi dikalangan ibu ibu ataupun orangtua, bahwa sebenarnya ibu-ibu sudah mengenal serta merasakan manfaat pijat bagi bayi.

Beberapa peserta bahkan telah menerapkan beberapa gerakan pijat pada bayinya sendiri namun terkadang masih merasa ragu apakah tekhnik yang di lakukan sudah benar atau belum. Manfaat yang diperoleh ibu ketika melakukan stimulasi pertumbuhan dan perkembangan melalui pijat bayi ini diantaranya dapat menjadikan bayi menjadi rileks (kualitas tidur bayi meningkat), menaikkan Berat Badan (BB) bayi serta menimbulkan ikatan batin yang kuat antara ibu dan bayi, bayi akan merasa nyaman karena pelaksanaan pijat bayi dilakukan dalam kondisi bayi yang menyenangkan. Jika pijat bayi ini dilakukan oleh orangtua maka akan timbul bounding antara bayi dan orangtua karena adanya sentuhan akan menimbulkan kasih sayang diantara keduanya. Hasil penelitian menunjukkan ada pengaruh pemijatan dengan bounding Attachment dimana pemijatan yang dilakukan sendiri oleh ibu menjadi media ibu dan bayi selelau berdekatan, menumbuhkan emosional yang positif lalu menumbuhkan kasih saying, serta menciptakan komunikasi antara bayi dan ibu [7]. Ikatan batin yang sehat sangat penting bagi anak terutama dalam usia 2 tahun pertama yang akan menentukan perkembangan kepribadian anak selanjutnya.[7]

Peningkatan berat badan bayi tentunya sangat dipengaruhi oleh pemberian pijat bayi yang diberikan secara kontinyu. Pada dasarnya bayi yang dipijat akan mengalami peningkatan kadar enzim penyerapan dan insulin sehingga penyerapan terhadap sari makan pun menjadi lebih baik, hasilnya bayi menjadi cepat lapar bahkan jika bayi sering menyusu maka dapat juga meningkatkan produksi ASI. Hasil penelitian menunjukkan $88 \%$ bayi yang dilakukan pijat secara kontinyu selama 10 hari saja mengalami kenaikan BB rata rata 925 gram [8]. Pemijatan meningkatkan penyerapan makanan oleh Nervouse Vagus sehingga nafsu makan bayi juga akan meningkatkan secara langsung BB bayi. [9]. Pijat bayi selain membuktikan efektifitasnya terhadap pertumbuhan dan perkembangan bayi juga akan memiliki system imunitas yang lebih tinggi dan menunjukkan sikap perkembangan motoric yang lebih cepat dibandingkan dengan bayi yang tidak dilakukan pijat secara kontinyu [8].

Hasil penelitian menunjukkan pemberian pemijatan berpengaruh terhadap peningkatan kemampuan mengontrol motoric kasar dan halus yaitu mampu mengontrol lengan, badan, tungkai bawah dan koordinasi jari tangan. Hal ini karna merangsang peredaran darah dan merubah energi karena adanya gelombang oksigen yang segar akan lebih banyak dikirim ke otak dan keseluruh tubuh. Pemijatan dapat pula menghasilkan efek biokimia berupa pertumbuhan yang optimal sehingga kemampuan motoric bertambah. [10]. Berdasarkan penelitian terdapat pengaruh pemijatan dengan meningkatkan kualitas tidur bayi rata rata $15.30 \mathrm{jam} / \mathrm{hari}$ sesudah dilakukan pemijatan dibandingkan sebelum dilakukan pemijatan yaitu rata-rata $11 \mathrm{jam} / \mathrm{hari}$ [11]. Diketahui bahwa tidurnya bayi yang berkualitas dapat membantu pertumbuhan bayi, hal ini disebabkan oleh adanya peningkatan kadar sekresi serotonin yang dihasilkan pada saat pemijatan. Serotonin merupakan zat transmitter utama yang menyertai pembentukan tidur dengan menekan aktifitas tidur lainya [11]. Serotonin akan disintesis dari asam amino trithophan yanga akan berubah menjadi melatonin, nah melatonin ini mempunyai peran dalam tidur yang lama dan lelap pada malam hari [11]. Ibu-ibu didusun Jati sangat antusias dalam pelaksanaan kegiatan ini, hal ini dapat dilihat dari berbagai pertanyaan yang diajukan oleh ibu ibu tentang pelaksanaan pijat bayi diantara pertanyaan yang diajukan adalah sebagai berikut, 
a. Apakah bayi boleh dilakukan pemijatan ketika suhu sedang naik atau demam?

b. Minyak apa yang aman digunakan untuk memijat bayi

c. Apa yang harus dilakukan ketika anak perut kembung

Pelaksanaan demonstrasi pijat bayi dimulai dengan mempersiapkan alat dan bahan ataupun persiapan awal yang harus dilakukan sebelum pemijatan yaitu persiapan ruangan yang hangat dan nyaman, minyak yang aman untuk bayi seperti minyak dari tumbuh tumbuhan. Selimut atau bisa menggunakan gedong bayi. Pelaksanaan demonstrasi pijat bayi ditunjukkan pada Gambar 1.

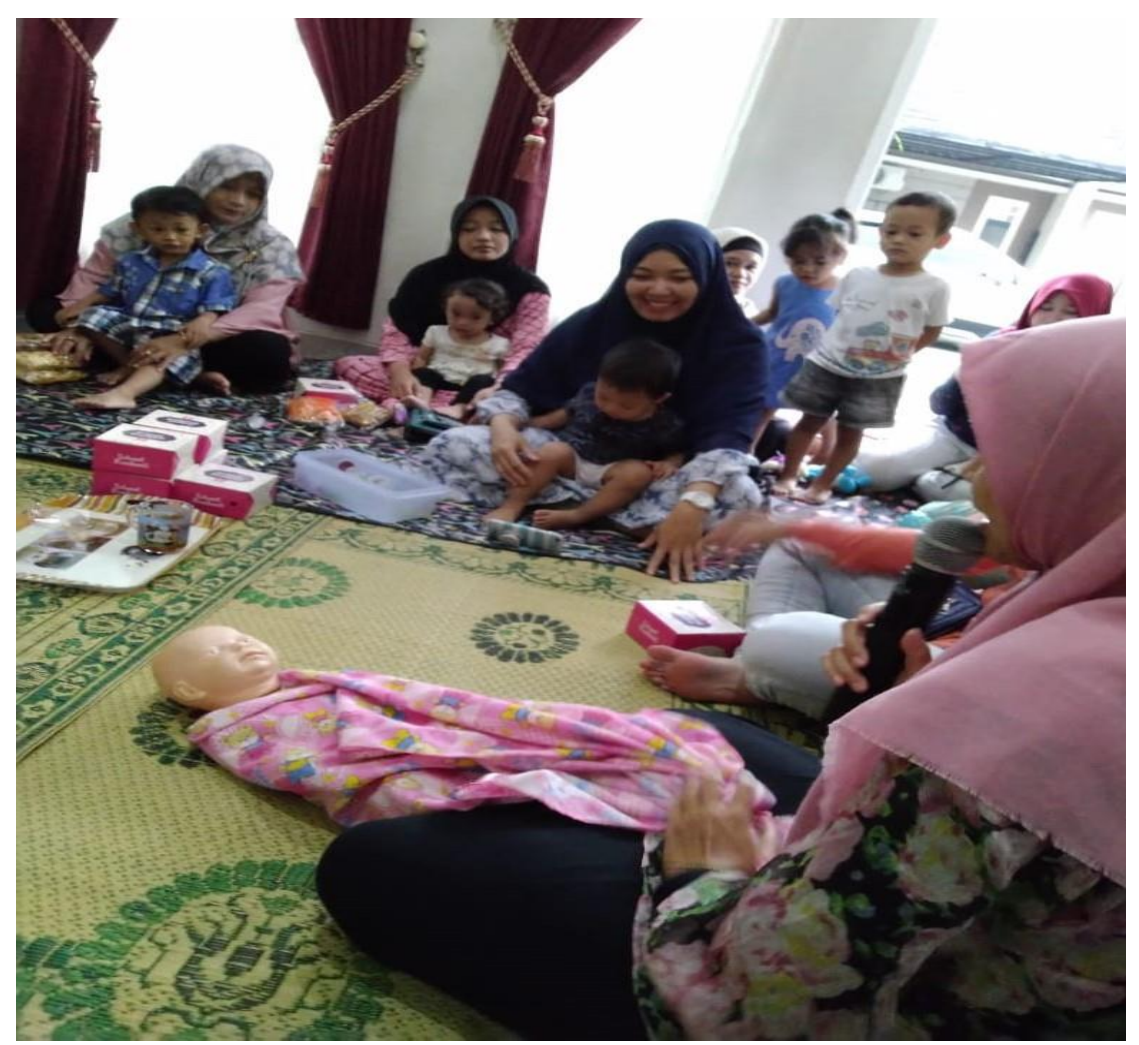

Gambar 1. Pelaksanaan edukasi pijat bayi

Demonstrasi pijat bayi ini dilakukan langsung menggunakan media phantom bayi, pada saat pelaksanaan demonstrasi tehnik pemijatan pada bayi, para peserta memperhatikan dengan cermat dan beberapa peserta yang membawa bayi langsung memperagakan tehnik pemijatan pada bayinya dengan pendampingan. Pada saat pelaksanaan pijat bayi orangtua sangat antusias dan bersemangat karena pelaksanaan dapat diterapkan langsung kepada anak dirumah. Orangtua bahkan menanyakan apa yang harus dilakukan untuk lebih meningkatkan kemampuan dalam perkembangan anak, pelaksanaan edukasi tentang pijat bayi dimulai dengan memberikan pengetahuan apa pengertian pijat bayi, tujuan dan manfaat yang diperoleh apabila dilakukan pijat bayi,serta hal hal apa yang perlu diperhatikan dan dipersiapan selama melaksanankan pijat bayi, pijat bayi akan banyak bermanfaat jika dilakukan dengan cara dan tehnik yang tepat.

Pada akhir kegiatan dilakukan evaluasi sejauh mana pemahaman peserta tentang edukasi cara menstimulasi pijat bayi, salah satunya dengan menanyakan beberapa pertanyaan tentang materi apa yang telah didisusikan serta meminta salah satu peserta untuk memperagakan tehnik pijat bayi yang benar pada pantom 
bayitersebut. Hasilnya Peserta mampu menjawab pertanyaan pengabdi dan mampu mempraktikkan gerakan pemijatan bayi meski pengabdi masih memperbaiki gerakan demonstran yang kurang tepat.

Kegiatan lain yang dilakukan juga adalah melakukan diskusi tentang pertumbuhan dan perkembangan pada anak mengenai pertumbuhan Berat Badan (BB) dan tinggi Badan (TB) pada bayi dan anak. Secara keseluruhan Kegiatan pengabdian kepada masyarakat ini berjalan dengan baik dan sesuai dengan rencana. Kegiatan pengabdian masyarakat di dusun Jati Wonokromo ini diharapkan dapat bermanfaat bagi orangtua. Semua peserta dapat mengikuti pelaksanaan edukasi dengan baik dan antusias serta bersedia untuk menerapkan dirumah secara langsung agar dapat meningkatkan pertumbuhan dan perkembangan bayi sesuai dengan usianya. Pemantauan penerapan pijat bayi dirumah akan dilakukan oleh Ibu RT dan paguyuban dusun Jati dan akan disampaikan oleh pengabdi untuk mengetahui kelanjutan dari kegiatan ini, karena merasakan manfaat pijat bayi berupa peningkatan kualitas tidur, nafsu makan, bounding attachment dan kenaikan berat badan dapat maksimal apabila pemijatan dilakukan secara kontinyu.

\section{Kesimpulan}

Pengabdian kepada masyarakat ini adalah sebagai upaya stimulasi perkembangan pada bayi melalui pijat bayi. Peserta sangat antusias dapat mengikuti serta dapat memahami tentang cara menstimulasi perkembangan bayi maupun anak Hal ini dapat dilihat dari hasil evaluasi dengan memberikan beberapa pertanyaan pada peserta dan semua pertanyaan dapat dijawab dengan benar pertanyaan dari pemateri dan ketika peserta diminta untuk mendemonstrasikan ulang, peserta dapat memperagakan dengan benar.

Saran terhadap orangtua untuk dapat memberikan stimulasi mulai dari bayi secara kontinyu sehingga akan mencapai pertumbuhan dan perkembangan dengan optimal dengan melaksanakan pijat pada bayi ketika dirumah, Selain stimulasi orangtua dapat juga untuk memantau pertumbuhan dan perkembangan pada anak sesuai dengan usia, sehingga jika terjadi ketidaksesuaian pertumbuhan dan perkembangan dapat diketahui secara dini.

\section{Daftar Pustaka}

[1] Roesli U. 2001. Pedoman Pijat Bayi Prematur dan Bayi Usia 0-3 Bulan. Jakarta: Trubus Agriwidya

[2] Kementerian Kesehatan. 2017. Keputusan Menteri Kesehatan No. 28 tahun 2017 tentang Izin dan Penyelenggaraan Praktik Bidan. Kemenkes:Jakarta

[3] Peraturan Menteri Kesehatan Republik Indonesia nomor 66 tahun 2014, tentang pertumbuhan, perkembangan dan gangguan tumbuh kembang anak

[4] Cristanti Y. Pengaruh Pendidikan Kesehatan Tentang Pijat Bayi Usia 1-12 Bulan Dengan Riwayat Bblr Terhadap Perilaku Ibu Memijat Bayi Di Wilayah Kerja Puskesmas Jangkar 2016Availablefrom:/citations?view_op=view_citation\&continue=/scholar \%3Fhl\%3Did\%26as_sdt\%3D0,5\%26scilib\%3D1\&citilm=1\&citation_for_v iew=dRzRgSkAAAAJ:9yKSN-GCB0IC\&hl=id\&oi=p

[5] Medise B, E (unit kerja koordinasi Tumbuh Kembang-pediatri Sosial IDAI), 2014, Stimulasi Pijat : Keamanan dan Manfaat, http://www.idai.or.id

[6]. Nurul, Kusmini, Sutarmi, 2017, Healthy Mom Baby Massage And Spa, IHCA, Semarang 
[7] Wahyuni, Sri,Dini Kurniawati, Hanny Rasni. 2018. Pengaruh Pijat Bayi Terhadap Bounding Attachment di Ruang Dahlia RSD dr. Soebandi Jember. E-Jurnal Pustaka Kesehatan, Volume 6Nomor2,Mei2018. https://www.google.com/search?safe=strict\&sxsrf=ALeKk02rNU3BbNZZ 0K589WOfuq9deyhOjA\%3A1607232906144\&ei=im3MX6GrCN--

3LUP9pmeyAI\&q=penelitian+tentang+pijat+bayi+terhadap+ikatan+batin

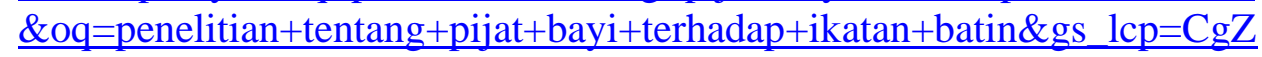
wc3ktYWIQAzIFCAAQzQI6BAgjECc6BQghEKABOgQIIRAVOgcIIRA KEKABUKTpCFiJ9whg6vkIaABwAHgAgAHrAYgBwuSAQU1LjcuMZgBAKABAaoBB2d3cy13aXrAAQE\&sclient=psyab\&ved=0ahUKEwihmMST0bjtAhVfH7cAHfaMBykQ4dUDCAw\&uact= $\underline{5}$

[8] Hutasuhut, A.S. 2018. Pengaruh Pijat bayi Terhadap Pertumbuhan (Berat Badan) bayi usia 1-3 Bulan di Wilayah Kerja Puskesmas Pematang Pasir Kota Tanjung Balai Tahun 2018. Skripsi Poltekes Kemenkes RI Jurusan kebidanan Medan Prodi DIV Kebidanan. http://repo.poltekkesmedan.ac.id/jspui/bitstream/123456789/737/1/SKRIPSI\%20FULL.pdf

[9] Syaukani, Aulia. 2015. Petunjuk Praktis Pijat, Senam, dan Yoga Sehat untuk Bayi agar Tumbuh Kembang maksimal. Yogyakarta: Araska.

[10] Suharto, Suriani, Arpandjam'an. 2018. Pengaruh Pijat Bayi Terhadap Peningkatan Motorik Kasar dan Motorik Halus bayi Usia 3-24 Bulan di Klinik Fisioterapi Sudiang Makasar. Media Kesehatan Politeknik Kesehatan. Vol.13 No 1. ISSN 1907-8153-ISSN 2549-0567. http://journal.poltekkes-

mks.ac.id/ojs2/index.php/mediakesehatan/article/view/99/23

[11] Sinaga, Asnita, Natalia Laowo. 2020. Pengaruh Pijat Bayi Terhadap Kualitas Tidur Bayi Usia 0-6 Bulan di BPM Pera Kecamatan Medan Tuntungan Tahun 2019. Excelent Midwifery Journal Jurnal Mitra Husada Volume 3 Nomor 1 April 2020. P-ISSN 2620-8237, E-ISSN 26209829. http://jurnal.mitrahusada.ac.id/index.php/emj/article/view/126 